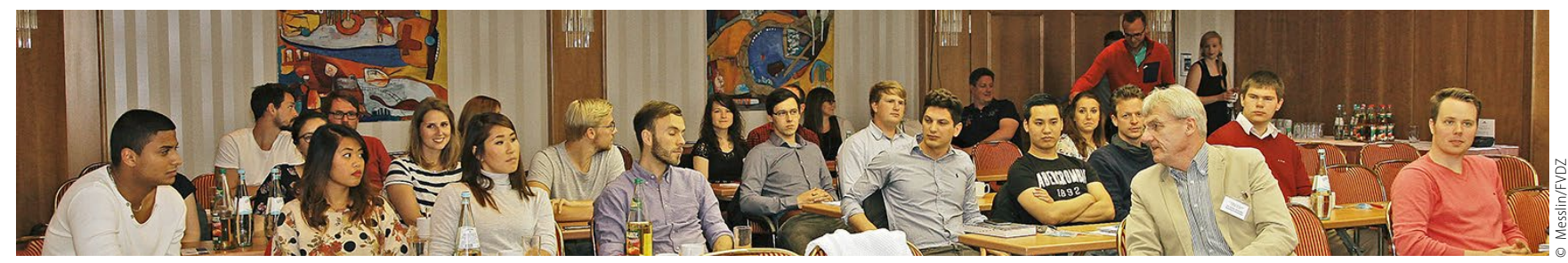

\title{
Rundum-Programm für den zahnmedizinischen Nachwuchs
}

Premiere beim Sommerkongress: Erstmals haben zwölf studentische Mitglieder des Freien Verbandes Deutscher Zahnärzte (FVDZ) eine Woche lang am Kongress teilgenommen. Die kostenfreien Plätze und die Unterkunft hatte der FVDZ über ein Gewinnspiel auf Facebook und über ein Mailing verlost. Neben der Teilnahme an den Seminaren und Referaten freuten sich die Gewinner über ein gemütliches Get-together und einen Bowlingabend. Dort tauschte sich der Nachwuchs in lockerer Atmosphäre mit Verbandsvertretern über die Arbeit des FVDZ und über berufspolitische Themen aus. In guter Tra- dition kamen am Abschlusstag 40 weitere Studenten der Universitäten Greifswald und Rostock dazu. In einem Vortrag informierte Dr. Susanne Woitzik von der ZA Zahnärztliche Abrechnungsgesellschaft AG (ZA AG) die Studierenden über das Thema: „Freiberuflichkeit - ja, bitte - mit Strategie zum Erfolg“. Ziel des Vortrages war es, die Nachwuchszahnmediziner für die Selbstständigkeit in der eigenen Praxis zu motivieren - frei nach dem IKEA-Motto: Entdecke die Möglichkeiten.

cas

\section{Stimmen der Studenten}

\section{Björn Vorpahl,}

4. Fachsemester Zahnmedizin, Friedrich-Schiller-Universität Jena

„Das ist mein erster FVDZ-Kongress. Für mich als Zahnmedizinstudent ist dieser Kongress eine absolute Bereicherung. Ich bilde mich weiter und kann mich gleichzeitig mit gestandenen Kollegen austauschen. Außerdem bekomme ich Einblicke in Themen, die man in den Lehrveranstaltungen an der Universität nicht erhält. Ein Highlight war der Workshop zu KompositFüllungen, in dem ich die erlernten Techniken gleich praktisch anwenden konnte.“

\section{Elisabeth Etzlinger,}

10. Fachsemester Zahnmedizin, LMU München

„Durch den FVDZ-Winterkongress in Ischgl bin ich auf den Geschmack gekommen. Ich wollte unbedingt auch bei der Fortbildungswoche auf Usedom dabei sein. Meine hohen Erwartungen an den Sommerkongress haben sich voll erfüllt. Für uns Studen-

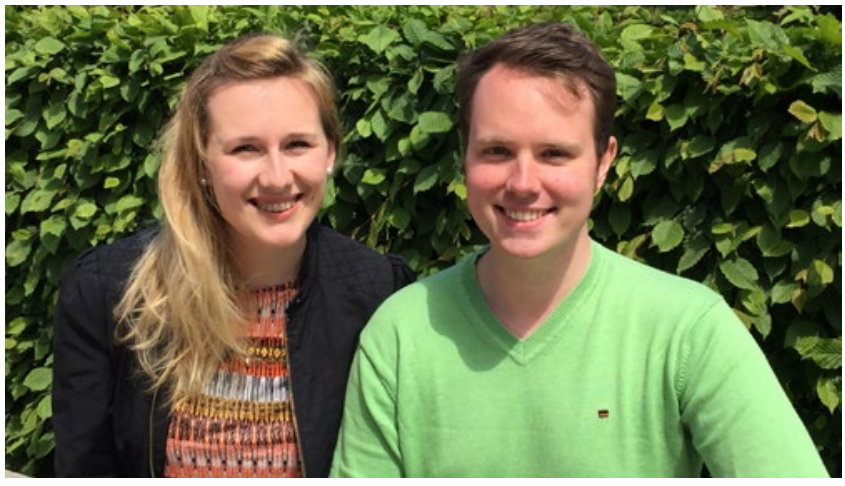

ten gab es ein perfekt organisiertes Programm mit einer tollen Unterkunft und verschiedenen Aktionen, bei denen wir uns in entspannter Atmosphäre mit dem Vorstand des Freien Verbandes austauschen konnten. In den Seminaren konnte ich über den Tellerrand der Uni hinausschauen und in den Pausen networken. Vor allem die Meeresluft und die wenigen Meter zum Meer machen diesen Kongress einfach besonders. Ich möchte definitiv im nächsten Jahr wiederkommen.“ 